International Conference on New Interfaces for Musical Expression

\title{
Architectural Systems \\ Sonification
}

\section{Brian Alexander}

Published on: May 20, 2021

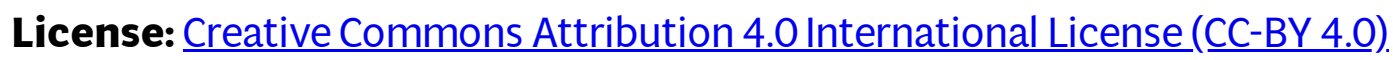




\section{Abstract}

Life has a sound track, but we only perceive a fraction of what's at play. The Architectural Sonificafion Project is an ongoing effort to give voice to automated systems and our interaction with them in the world. When these sub-currents and activities are brought to life as an auditory experience, their greater depth and complexity become more fully apparent. Though the project has a strong data component, the aspect of play is purely physical, personal, and sensitive to choice. A vent which appears to only blow out air has in fact a myriad of every variable vortices, velocities, and gradients. It is hoped that this effort can bridge a general awareness for all of us to slow down and look beneath the surface we unconsciously apply to our daily lives.

\section{Project Description}

The Architectural Systems Sonification project is one of a series of site specific installations aimed at giving a voice to everyday objects and systems which are largely taken for granted and ignored. The project is intended to highlight and express the hidden subtleties of each system in an artistic manner thereby triggering an awareness of other autonomous systems in our lives.

I am currently focused on HVAC as a pilot sketch but will be expanding to lighting and other aspects 1st and 2nd quarter 2021. HVAC, (heating, ventilation, and air conditioning) is a system of equilibrium. It is equivalent roughly to homeostasis in biological terms. When it is performing correctly, it renders itself invisible - making it a topic of interest on several levels. For this project I designed and built two styles of sensors to interact with air flow and light which then modulate synthesized sound within a predetermined format. It was revealed through this process that in a typical system, all inlet and output points flow at slightly different rates and begin and end at different times. The frequency and duration of the system's run time is tied directly to it's set point but varies widely by the time of day, weather, season, and occupants. When these variables are brought to life as an auditory experience, it's greater depth and complexity become clearer such that it seems more alive than the apparently colorless background device it appears to be. It is hoped that this experience bridges a general awareness for all of us to slow down and look beneath the hardened surface we've unconsciously applied to our daily lives. 


\section{Installation Notes}

The installation would be offered in a documented video format. All components, installation, site work and documentation would completed by myself.

\section{Installation Requirements}

There would be no requirements as it is offered as video documentation of the installation.

\section{Media}

\section{Visit the web version of this article to view interactive content.}

\section{Architectural Sonification}

\section{Acknowledgments}

The author would like to thank... My friends, family and all the explorers and teachers before me for which I am eternally grateful. 